\title{
INDEPENDENT WORK OF STUDENTS AS THE LEADING FORM OF EDUCATIONAL PROCESS ORGANIZATION AT THE UNIVERSITY
}

\author{
Predtechensky Boris ${ }^{1}$, Fomina Marina ${ }^{2}$ \\ ${ }^{1}$ Sergeevich Cand. of Phys.-Mat. Sciences, Associate Professor, e-mail: borpred@ mail.ru \\ ${ }^{2}$ Vasilyevna Cand. of Phys.-Mat. Sciences, Associate Professor, e-mail: fomina1946@gmail.com \\ National Research Moscow State University of Civil Engineering 26, Yaroslavskoye Shosse, Moscow, \\ 129337, Russian Federation
}

\begin{abstract}
The article is devoted to independent work of students at the University. It analyzes different types of independent work. The author focuses on independent work of students as the leading form of educational activity in which a student must learn to acquire and use knowledge in practice independently, to take initiative in task performance, to use a creative approach to work.
\end{abstract}

Keywords: independent work, forms of independent work, extracurricular independent work, the independent work at the University, the scientific work of a student.

\section{INTRODUCTION}

After the transition to a two-tier system of training, a significant change of student teaching methods took place. The number of lecture classes with a teacher (both lectures and practical classes) has decreased significantly. Many sections of the curriculum are provided to students for self-study. Besides, they changed the requirements for a university graduate. The traditional system of higher education is designed to acquire knowledge and skills. Competence, the ability of independent search for knowledge and the need to acquire this knowledge become the priority in new conditions [1].

In many industries, research is conducted on the quality of graduate training. The results of such studies have shown that there is not enough qualified civil engineers in all regions. As is known, the construction industry was a powerful engine of the economy of that period [2]. A number of entrepreneurs note a low professional level of a modern young expert. The competences of young experts demanded by the majority of managers of different regions include the ability to apply professional theoretical knowledge in practice, the ability to find solutions in unusual situations and the ability to work with large volumes of information. At present, the construction business has a great demand in engineers not only with the theoretical knowledge in their field, but also in those who are able to apply this knowledge in practice. In order to give university graduates a chance to achieve certain successes in their profession, it is necessary to combine general theoretical training with the acquisition of professional skills, the modification of the educational process is necessary. During the learning process a future civil engineer should be acquainted with the basics of his future profession, should get an idea of work system at a construction site.

An independent work of students can be either an audience one under the direct supervision of a teacher or an out-of-class one, both with the participation of a teacher and without him. Auditor work is carried out at a lecture, practical or laboratory classes. Extracurricular activities - include the study of scientific and specialized literature, the preparation for classes, the preparation of reports, the writing of abstracts and the scientific work of students.

One of the forms of a student's out-of-class independent work is the preparation for a lecture, which consists of working out the issues of a lecture topic according to teaching and methodological manual, a textbook, the critical analysis of the studied material, the posing of the questions of interest. Self-preparation to a lecture provides an opportunity for a deeper understanding of the lecture material. Many students perform preliminary works on lecture material, on textbooks and teaching aids, which gives them the opportunity to understand a lecture better. An attentive work during a lesson, a short but legible record of the material 
outlined in a lecture, the clarification of the main issues is an indispensable condition for further successful independent work.

An equally important form of independent student work is the preparation for practical classes. Practical classes are given for almost all the disciplines studied at a university. These lessons concretize and expand the knowledge gained during lectures, give the opportunity to master this knowledge at a higher level, help to consolidate the knowledge and skills gained during the learning process.

The modern level of expert training requires the development of their research skills. This can be achieved in the process of technical discipline study during a laboratory workshop. A laboratory workshop should be multi-level one, it should have the works with different levels of complexity, designed for the students with different initial training on this discipline. It is the laboratory workshop that ensures the development of a student creative potential, raises the interest in teaching and research activities. Performing the works of a laboratory workshop, students learn the program material better. Previously seemingly abstract definitions and formulas, become quite specific and are perceived in a completely different way. The connection between theory and practice takes place.

Laboratory works should differ not only by the level of solved task complexity, but also by the methodology of its conduct. Depending on the assigned tasks, various forms of a laboratory workshop organization can be implemented. At the initial stage of a discipline study, it is better to use a frontal or a cyclic method of laboratory work performance. In the process of these types of work performance, students acquire the necessary skills of measuring and reporting according to work results. During the next stage you can apply an individual form of work organization for the most successful students. This form of work organization allows to expand the scope of the works performed and gives an opportunity for students to show their independence in research conduct.

When laboratory works are performed, several types of approach to their implementation can be applied:

- at the initial stage of training works are carried out with a strict control over student activities;

- then, a partially search method is used for the main part of the students with less strict control over their work on a teacher's part;

- research work is carried out with a teacher's indirect control for most prepared students.

In the process of a research laboratory work performance, a teacher plays the role of a scientific adviser, a consultant, but not a controller. The students, performing independent research work, go all the way of researchers who conduct real scientific work.

The technique of performed work protection plays an important role in laboratory practice performance. The protection is organized most effectively in front of a group of students. Usually they ask a lot of questions, and discussions appear often. This contributes to a discipline deeper study.

The main types of research work of students (RWS), along with the teaching and research work, provided by the curriculum of the department, is RWS during after-hours. The forms of this type of work include student scientific circles, problem groups, sections, laboratories, the participation in scientific conferences, the performance of competitions among student scientific works.

A student scientific circle provides ample opportunities for interesting, diverse, independent work and contributes to the development of an active creative personality. In such circles, students learn to work with scientific literature, to plan and carry out research, to increase their knowledge independently and to navigate the flow of scientific literature. Many students manage to make their first steps in the world of science, to conduct independent experiments, to release their first scientific work during their activity in a circle. The members of the circle train the skills of independent work with modern scientific equipment, generalize the obtained results, and formulate the conclusions on the results of the performed studies. A correctly organized 
research work of students contributes to an in-depth assimilation of academic disciplines and to the development of one's own opinion on the issues under consideration. There are the following important qualities for a future researcher: responsibility, the ability to defend his own point of view and creative thinking. They are developed most often when they perform research work in student circles.

For some students, the work in academic circles consists in a deeper study of individual topics and issues. The most prepared students study a wide range of issues, often going beyond a course curriculum. Usually, they consider the phenomena and the problems related to the field of scientific interests of a circle head. This is due to the fact that a department has the necessary modern scientific equipment to study these problems. In this case, a group of students is selected which is particularly interested in this scientific problem. The most capable students are selected in the process of work. They identify the leaders in a student group who are ready to lead the work, and random people are taken away. Thus, there are small stable groups of several people who are interested to solve set tasks. As a rule, these groups continue their work even when the students complete their studies at this department.

For the most part of students, research topics should be close to the future professional activity of graduates, when the motivation for continuing scientific work takes place. For example, the topics of student works at the Department of Physics of MGSU were represented by the issues related to the properties of building materials and physical phenomena arising during the construction and the operation of structures. A new cycle of works is being developed on the basis of building aerodynamics laboratory equipped with the most modern equipment at the Department of Physics and Building Aerodynamics for the most prepared students. In this series of works, the methods of their conduct and protection differ substantially from the methods of standard laboratory work conduct. Often the work in problem groups, sections and laboratories unites the students of various university courses and faculties. Usually such groups provide the possibility of a much deeper and more comprehensive study. The work in such groups is an important step on the way to independent scientific work.

It is necessary to pay attention to the ability of students to present the results of their work in the form of scientific reports. The purpose of the scientific reports is the development of student ability to popularize difficult questions, to stick to the audience, to participate in the discussion on scientific topics. Student scientific conferences take place for many years in order to activate the educational process and to develop the students' ability to defend their point of view confidently at the Department of Physics at MGSU. The topics of scientific papers, the results of which are reported at conferences, are related to the problems that engineers-builders have to deal with after their graduation. These include the problems of mechanics, hydrodynamics, molecular physics and thermodynamics, optics and acoustics. Among the goals of the works performed by students, we can distinguish such as the ability to build the models of complex physical processes, to use similarity methods, dimensional theories, the ability to make approximate estimates, and interpret the results of experiments and numerical calculations intelligently. If during the senior courses and the study physical processes the main attention is paid to the standard methods of calculation and repeatedly tested techniques, then the causes of these processes and phenomena emergence are considered at the conferences of the Department of Physics. For example, they study why the temperature distribution does not depend on material at a stationary temperature field, but as soon as the conditions change to non-stationary ones, the properties of the material begin to play a decisive role. At the conferences students' listen to the reports on the most topical issues: such as the issues of ecology and environmental protection, the problems associated with the use of alternative energy sources. The reports on what physical phenomena can be used to create renewable energy sources, the ways of such source efficiency estimation, the ways of their increase are of great interest and are the source of active discussions. When the problems of the environment preservation are solved the basic attention is given to the pollution of air by various impurities. In order to solve this problem, we consider the problem of aerosol particle motion in air, the behavior of an aerosol cloud, and the processes of aerosol particle scattering.

Subject Olympiads are an effective form of work with students. The participation of students in competitive events is an important component to improve the quality of creative, competent professional training. In recent years, up to half of university graduates participate in subject Olympiads [3]. The Olympiads are held to identify the quality of graduate training, to consolidate and deepen the knowledge and skills acquired 
during the training process. Usually the Olympiad problems are more complex than standard audit tasks. In order to solve them, you need not only good knowledge of this discipline, but also the ability to systematize and generalize the information received earlier. The participation in student subject Olympiads contributes to the development of creative abilities, the deepening of knowledge, instills the skills of individual work and team work. Olympiads allow to identify active students, helping them to gain some confidence in their abilities. Subject Olympiads have taken firmly their place in the system of student training as future specialists. Besides, the participation in the Olympiads leads to the development of interest in the subject under study, the promotion of focus on achievements and the development of a future expert character.

Another great benefit of the Olympiads is that they are attended not only by well-performing students, but also by the students with poor academic performance. The participation of such students in a serious competition increases their interest in a subject significantly and stimulates the motivation for the learning process, activity and independent work with additional literature. Olympiad is the result of a teacher and a student work not only during training sessions, but also during after-hour activities. In the process of preparation for the Olympiads, the relationships are changed between the students and the teachers involved in Olympiad organization and preparation. "Common interests" appear among teachers and students, a mutual understanding develops between them, which is the condition for trainee general competence development. During the preparation for the Olympiad, held with a group of students, the specifics of teamwork during the competitions makes them get accustomed to collective creativity, to the work of each group member in constant interaction with other group members. The main requirement during the organization of the Olympiads is the involvement of as many students as possible in cognitive acti vities, the encouraging of students to deepen their knowledge and develop common competencies. It is desirable to use the tasks based on the material of real situations arising in professional activity, which in the course of their solution significantly expand the area under study during the olympiads, especially for technical experts [4].

The participation in an Olympiad, allows students to take a step in their development, to see their shortcomings, their capabilities, their prospects and their strengths. After the Olympiads, an active work of students does not cease, does not stop, but allows to reach a new level. At the same time, the Olympiads retain their pedagogical mission concerning the preparation of students for the activities in the conditions of stress and psychological discomfort. The experience of the Olympiad movement organization, the analysis of work with students shows that the quality of higher technical education can be provided at a higher level if the Olympiad movement is organized at some new level in educational institutions. A new level includes the collective activity of students in groups to prepare for an Olympiad, led by a teacher and their independent work. This applies both to the stage of preparation for an Olympiad, and to the competition stage.

\section{REFERENCES}

Aminov I. B., D. F. Khodjaev (2017). [Modern technology for the effective organization of independent work of students]. Molodoj uchenyj. [Young scientist]. No. 3. pp. 523-524. (In Russ., abstract in Eng.)

future engineers (for example, building specialties)] Problemy sotsial'no-ehkonomicheskogo razvitiya Sibiri.[Problems social-economic development of Siberia]. No. 2. pp. 102-109. (In Russ., abstract in Eng.)

Ivaschenko G. A., Kamchatka V. M. (2010). [ Development of professional motivation

L. I. Petrova . Kutergina. L. I. (2008). [ Methodological support of the Bologna process in higher education institution (pedagogical aspect)] Rostov n/D : Feniks, p. 649. (In Russ., abstract in Eng.)

Popov A. I., Puchkov N. P. (2010). [Olympiad movement management in higher education]. Obrazovanie $i$ samorazvitie (Kazan). [Education and self-development] (Kazan, Russia). № 3 (19). pp. 75-81. (In Russ., abstract in Eng.) 